\title{
Cardiovascular effects of intravenous midazolam after open heart surgery
}

\author{
Lara Shekerdemian, Andrew Bush, Andrew Redington
}

\begin{abstract}
Midazolam is the sedating agent of choice in many paediatric intensive care units, and is usually administered as a continuous intravenous infusion with or without a preceding bolus dose.

Ten haemodynamically stable children, ventilated in the early postoperative period after cardiac surgery and receiving intravenous morphine infusions, were given an intravenous bolus followed by a continuous infusion of midazolam. Haemodynamic data were recorded before the bolus, and 15 minutes and one hour later. A bolus of midazolam lowered the cardiac output by $24.1 \%$. Arterial blood pressure, oxygen consumption, and mixed venous oxygen content fell significantly. There was a tendency for all variables subsequently to recover towards baseline values, within one hour, during a continuous infusion.

An intravenous bolus of midazolam causes a transient but unwanted fall in cardiac output. It is suggested that in children who are receiving intravenous opiates, its use in the early postoperative period be limited to a continuous infusion. (Arch Dis Child 1997;76:57-61)
\end{abstract}

Keywords: cardiac output; sedation; midazolam; cardiac surgery.

An ideal intravenous sedating agent for use in intensive care should have a rapid onset of action, a short half life, and as far as possible its effects should be limited to the target organthe central nervous system. Midazolam, a relatively new benzodiazepine, is an agonist at the benzodiazepine receptor - a subunit of the central neuroinhibitory $\gamma$-aminobutyric acid-A receptors. ${ }^{1}$ Midazolam can be administered as an intravenous bolus or as a continuous infusion, and its desirable clinical effects range from anxiolytic to hypnotic depending on the percentage of receptor occupancy rather than plasma concentrations of the drug. ${ }^{2}$

The cardiovascular effects of intravenous midazolam have been studied in healthy volunteers and in various adult patient groups, with most investigators reporting a transient fall in systolic and diastolic blood pressures. ${ }^{3-5}$ However, intravenous midazolam has varyingly been shown to reduce or have no effect on both the cardiac output and the systemic vascular resistance. ${ }^{4-6}$

It is usual to see a transient fall in systemic blood pressure after an intravenous bolus of midazolam in children on the paediatric cardiac intensive care unit, but there are few published data concerning the cardiovascular effects of midazolam in children after cardiac surgery-where even minor changes in cardiac output and haemodynamics may be particularly undesirable.

\section{Aims and objectives}

Intravenous midazolam is the agent of choice for sedating ventilated patients in many paediatric intensive care units including our own, and is usually administered as a continuous infusion with or without a preceding bolus dose. $^{78}$ At the time of this study it was our usual practice to start an intravenous infusion of morphine in all children returning from the operating theatre after cardiac surgery. If a longer period of sedation and ventilation were anticipated, then intravenous midazolam would be used in addition to morphine, and in haemodynamically stable patients an intravenous infusion of midazolam would be preceded by a bolus dose. In this study we have investigated the cardiovascular effects of an intravenous bolus of midazolam followed by a continuous infusion during the early postoperative period in a group of children undergoing open heart surgery at the Royal Brompton Hospital, London.

\section{Patients}

The patients in this study group were part of a large cohort of children undergoing detailed cardiovascular monitoring in the early postoperative period after open heart surgery. Patients with an initial cardiac index of less than 3.5 $1 / \mathrm{min} / \mathrm{m}^{2}$ were not considered for inclusion in this study and patients receiving more than one inotropic agent were also excluded. We prospectively studied the haemodynamic effects of intravenous midazolam in 10 ventilated children (median age 3.3 years) who were already receiving an infusion of morphine $(40 \mu \mathrm{g} / \mathrm{kg} /$ hour) in the early postoperative period after cardiopulmonary bypass. The anthropometric data for each patient with details of cardiac surgery and inotropic treatment at the time of study are given in table 1.

\section{Methods}

ANAESTHESIA

Patients were all premedicated with oral trimeprazine $1.5 \mathrm{mg} / \mathrm{kg}$, atropine $30 \mu \mathrm{g} / \mathrm{kg}$, and morphine $0.5 \mathrm{mg} / \mathrm{kg}$ (triatromorph). Induction of anaesthesia was either with an inhalational agent (isoflurane $1-2 \%$ in $100 \%$ oxygen) in eight patients, or with intravenous thiopentone 
Table 1 Patient details

\begin{tabular}{lcll}
\hline Patient No & Age (years) & Operation & Inotropes $(\mu \mathrm{g} / \mathrm{kg} / \mathrm{min})$ \\
\hline 1 & 1.6 & VSD repair + relief RVOTO & DA 4 \\
2 & 13.6 & MVR & DA 5 \\
3 & 3.8 & TCPC & DA 6 \\
4 & 6.8 & TCPC & DA 10 \\
5 & 13.0 & Correction TOF & DA 8 \\
6 & 0.4 & VSD closure & DA 5 \\
7 & 4.7 & MVR & None \\
8 & 4.1 & ASD repair & DA 6 \\
9 & 0.4 & ASD repair & None \\
10 & 1.6 & VSD repair & DA 3 \\
\hline
\end{tabular}

ASD = atrial septal defect $; \mathrm{DA}=$ dopamine MVR $=$ mitral valve replacement RVOTO $=$ right ventricular outflow tract obstruction; TCPC $=$ fenestrated total cavopulmonary connection; TOF $=$ tetralogy of Fallot; VSD = ventricular septal defect.

$(5 \mathrm{mg} / \mathrm{kg}$ ) in two children. All children were nasally intubated with cuffed endotracheal tubes (Mallinkrodt Medical). Anaesthesia was subsequently maintained with inhaled isoflurane, with additional bolus doses of intravenous fentanyl $(8-15 \mu \mathrm{g} / \mathrm{kg})$ and pancuronium $(0.2-0.3 \mathrm{mg} / \mathrm{kg})$. All patients received an intravenous bolus of pancuronium $(0.2-0.3 \mathrm{mg} / \mathrm{kg})$ and fentanyl $(10-20 \mu \mathrm{g} / \mathrm{kg})$ after discontinuation of cardiopulmonary bypass and less than two hours before starting the study. No child received intravenous midazolam at any time before the study. On return to the intensive care unit from the operating theatre, patients were ventilated using volume cycled intermittent positive pressure ventilation, and intravenous infusions of morphine $(40 \mu \mathrm{g} / \mathrm{kg} / \mathrm{hour})$ and vecuronium $(40-60 \mu \mathrm{g} / \mathrm{kg} /$ hour) were started.

\section{CARDIOVASCULAR MEASUREMENTS}

All children had continuous invasive monitoring of systemic blood pressure, pulmonary arterial and right atrial pressures, with additional left atrial pressure monitoring in four patients. Heart rate was monitored noninvasively.

Pulmonary blood flow was measured using the direct Fick method (see below). This requires measurement of mixed venous and arterial oxygen content, and oxygen consumption. No child had echocardiographic evidence of a residual intracardiac left-to-right shunt. Patients 3 and 4 (see table 1) had a minimal right-to-left shunt (1.0:1.1) across a surgically created baffle fenestration, and in these two children, the shunt fraction did not alter during the study period. Pulmonary blood flow has

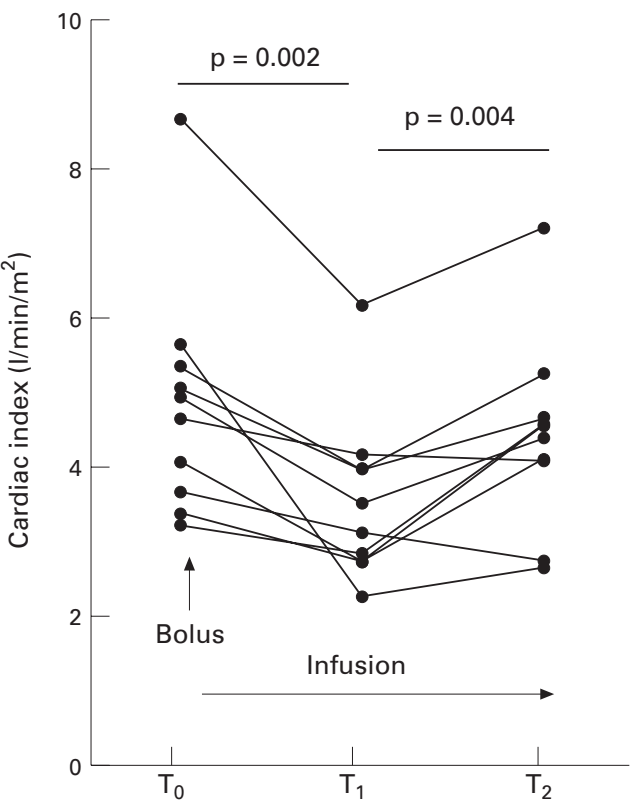

Figure 1 Effect of intravenous midazolam on cardiac output. Values for individual patients are shown. $T_{0}=$ prebolus values; $T_{1}=$ values 15 minutes after bolus (and during a continuous infusion); and $T_{2}=$ values one hour after a bolus (also during an infusion). The mean cardiac index fell by $24.1 \%$ after an intravenous bolus and then increased towards prebolus values during a continuous infusion.

therefore been used to represent cardiac output for all patients.

An arterial blood sample was sent for haemoglobin estimation before beginning the study. Mixed venous oxygen content was calculated from pulmonary arterial blood samples, and arterial oxygen content-from left atrial, peripheral arterial, or pulmonary venous samples. Oxygen consumption was measured using on-line respiratory mass spectrometry; this is a highly sensitive and accurate method of continuous gas analysis which allows simultaneous measurements of multiple gas fractions within a mixture. A mass spectrometer (Amis 2000, Innovision A/S, Odense, Denmark) was adapted for use on ventilated children on the intensive care unit, and oxygen consumption was measured using the mixed expirate inert gas (argon) dilution method. ${ }^{9}$ This requires analysis of inspired and expired gases, and collection of all expired gas. We have previously

Table 2 Group data showing the cardiovascular effects of intravenous midazolam. Data are expressed as mean (SE)

\begin{tabular}{|c|c|c|c|}
\hline \multirow{3}{*}{$\begin{array}{l}\text { Haemodynamic variable } \\
\text { Cardiac index }\left(1 / \mathrm{min} / \mathrm{m}^{2}\right)\end{array}$} & \multirow[b]{2}{*}{ Prebolus $\left(T_{0}\right)$} & \multicolumn{2}{|c|}{ On intravenous infusion } \\
\hline & & $15 \min \left(T_{\nu}\right)$ & 1 hour $\left(T_{2}\right)$ \\
\hline & $5.1(0.5)$ & $3.7(0.4) \dagger$ & $4.6(0.4) \S$ \\
\hline Oxygen consumption $\left(\mathrm{ml} / \mathrm{min} / \mathrm{m}^{2}\right)$ & $266 \quad(23)$ & $222 \quad(20) \dagger$ & $243 \quad(24)$ \\
\hline Mixed venous oxygen content $(\mathrm{ml} / 100 \mathrm{ml}$ blood) & $12.3(0.9)$ & $11.6(0.7)^{\star}$ & $12.2(0.7) \ddagger$ \\
\hline Heart rate (beats/min) & $125 \quad(9)$ & $123 \quad(8)$ & 130 (8)ฐ \\
\hline Stroke volume $\left(\mathrm{ml} / \mathrm{m}^{2}\right)$ & $41.8 \quad(6.5)$ & $33.1(4.9) \dagger$ & $39.6(4.7)$ \\
\hline Systolic blood pressure (mm Hg) & $103 \quad(7.3)$ & $83 \quad(6.0) \dagger$ & $89 \quad(3.7)$ \\
\hline Diastolic blood pressure (mm Hg) & $(3.5)$ & $(3.2)^{\star}$ & $(2.2)$ \\
\hline Mean arterial pressure $(\mathrm{mm} \mathrm{Hg})$ & (4.7) & $(3.9) \dagger$ & (2.4) \\
\hline Right atrial pressure $(\mathrm{mm} \mathrm{Hg})$ & $11 \quad(1.1)$ & $10 \quad(1.0)$ & $11 \quad(0.8)$ \\
\hline SVRI (units $/ \mathrm{m}^{2}$ ) & $11.7 \quad(1.2)$ & $13.5(1.2)$ & $12.2(1.8)$ \\
\hline PVRI (units $/ \mathrm{m}^{2}$ ) & $0.96(0.3)$ & $1.63(0.5)$ & $1.25(0.5)$ \\
\hline
\end{tabular}

PVRI = pulmonary vascular resistance index; SVRI = systemic vascular resistance index

* Haemodynamic change between $\mathrm{T}_{0}$ and $\mathrm{T}_{1}: \mathrm{p}<0.05$; thaemodynamic change between $\mathrm{T}_{0}$ and $\mathrm{T}_{1}: \mathrm{p} \leq 0.01 ; \ddagger$ haemodynamic change between $T_{0}$ and $T_{2}: p<0.05 ; \S$ haemodynamic change between $T_{1}$ and $T_{2}: p \leq 0.01 ; \uparrow$ haemodynamic change between $T_{0}$ and $\mathrm{T}_{2}: \mathrm{p}<0.05$. 


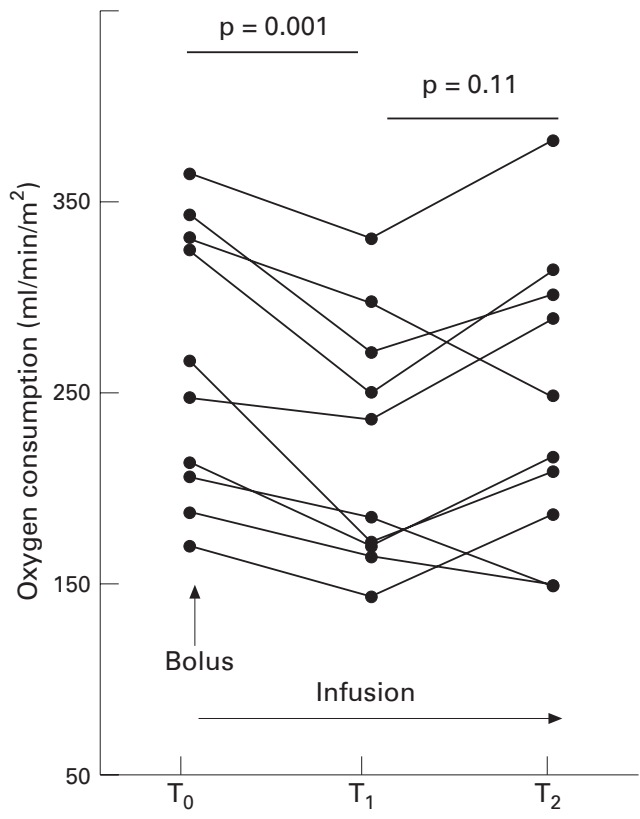

Figure 2 Effect of intravenous midazolam on oxygen consumption. The mean oxygen consumption fell by $16.5 \%$ after an intravenous bolus of midazolam and tended subsequently to increase towards baseline, although this increase was not statistically significant.

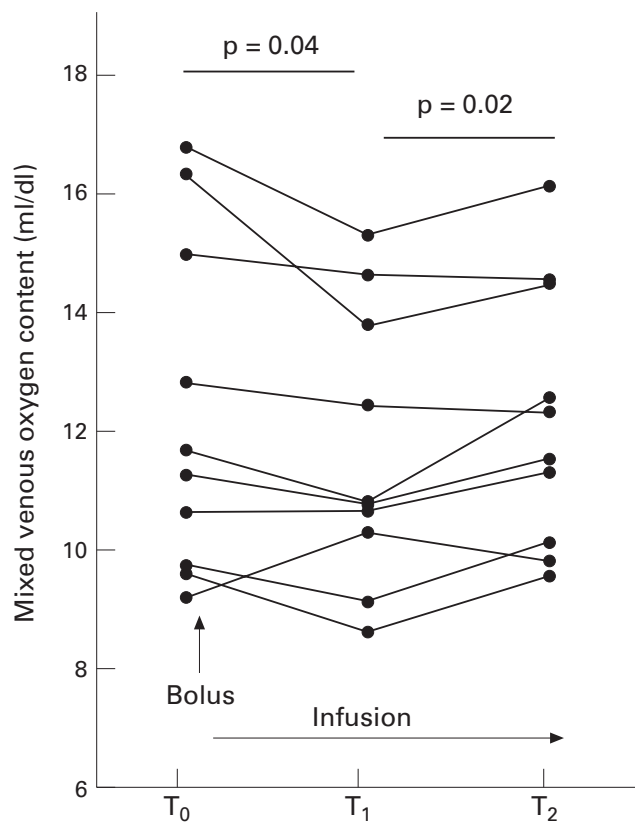

Figure 3 Effect of intravenous midazolam on mixed venous oxygen content.

described in detail our method of measurement of oxygen consumption together with the modifications required for gas collection within the ventilator circuit. ${ }^{10}$

PROTOCOL

Before beginning the study, the cuff of the endotracheal tube was inflated, and leakage around the tube was excluded by sampling for carbon dioxide using one of the mass spectrometer inlets, thus ensuring collection of all expired gas. Monitoring of oxygen consumption was then started. An intravenous bolus $(0.1 \mathrm{mg} / \mathrm{kg})$ of midazolam was given to each child, and after this, a continuous infusion was immediately started at $0.10-0.2 \mathrm{mg} / \mathrm{kg} / \mathrm{hour}$.

Three sets of cardiovascular measurements (cardiac output, systemic blood pressure, pulmonary artery pressure, right and left atrial pressures, and heart rate) were made: the first, immediately before the intravenous bolus of midazolam (time $\mathrm{T}_{0}$ ); the second, 15 minutes later and during a continuous infusion (time $\mathrm{T}_{1}$ ); and the third, again during a continuous infusion, one hour after the bolus dose (time $\mathrm{T}_{2}$ ). No other changes were made to pharmacotherapy during the study period.

HAEMODYNAMIC CALCULATIONS (see appendix for abbreviations)

$\mathrm{CI}\left(1 / \mathrm{min} / \mathrm{m}^{2}\right)=\frac{\dot{\mathrm{VO}}_{2}}{\mathrm{CaO}_{2}-\mathrm{CvO}_{2} / \mathrm{BSA}}$

$\mathrm{CAO}_{2}(\mathrm{ml} / \mathrm{dl}$ blood $)=$

$$
\frac{\mathrm{SAO}_{2} \times 1.34 \times \mathrm{Hb}}{100}+\left(\mathrm{PaO}_{2} \times 0.003\right)
$$

$\mathrm{CvO}_{2}(\mathrm{ml} / \mathrm{dl}$ blood $)=$

$$
\frac{\mathrm{SvO}_{2} \times 1.34 \times \mathrm{Hb}}{100}+\left(\mathrm{PvO}_{2} \times 0.003\right)
$$

SVRI $\left(\mathrm{UNITS} / \mathrm{M}^{2}\right)=\frac{\text { MAP }- \text { RAP }}{\mathrm{CI}}$

PVRI $\left(\mathrm{UNITS} / \mathrm{M}^{2}\right)=\frac{\text { MPAP }-\mathrm{LAP}}{\mathrm{CI}}$

STATISTICAL ANALYSIS

Group data are expressed as mean (SE). Data were analysed using the analysis of variance test for repeated measures with the Bonferroni correction for multiple comparisons.

\section{Results}

Results are given in table 2 . The mean cardiac index (fig1) at $\mathrm{T}_{0}$ was $5.1(0.5) \mathrm{l} / \mathrm{min} / \mathrm{m}^{2}$, and at $\mathrm{T}_{1}$ had fallen to $3.7(0.4) \mathrm{l} / \mathrm{min} / \mathrm{m}^{2}$. Thus a bolus of intravenous midazolam caused the cardiac index to fall by $24.1(4.7) \%(\mathrm{p}=0.002)$. The cardiac index subsequently increased to 4.6 (0.4) $1 / \mathrm{min} / \mathrm{m}^{2}$ at $\mathrm{T}_{2}(\mathrm{p}=0.004$ compared with $\mathrm{T}_{1}$ ), and there was no significant difference between $\mathrm{T}_{0}$ and $\mathrm{T}_{2}(\mathrm{p}=0.27)$. Oxygen consumption (fig 2) fell by $16.5(2.9) \%$ between $T_{0}$ and $T_{1}(p=0.001)$, and in all but three patients rose towards baseline values at $\mathrm{T}_{2}(\mathrm{p}=0.11)$. Mixed venous oxygen content (fig 3) also fell between $T_{0}$ and $T_{1}(p=0.04)$ and increased to baseline values at $\mathrm{T}_{2}(\mathrm{p}=$ 0.02 ). The pattern of changes in cardiac output with intravenous midazolam was accompanied by similar changes in systolic and diastolic blood pressures. The mean arterial pressure (fig 4) fell significantly between $\mathrm{T}_{0}$ and $\mathrm{T}_{1}(\mathrm{p}=$ $0.004)$, and then tended to increase between $T_{1}$ and $T_{2}(p=0.05)$, with no overall change between $T_{0}$ and $T_{2}(p=0.11)$.

Patient 2 was atrially paced. The heart rate was recorded in eight patients, and did not change significantly between $T_{0}$ and $T_{1}(p=$ $0.59)$ but rose slightly from $T_{1}$ to $T_{2}$ (p $=$ 


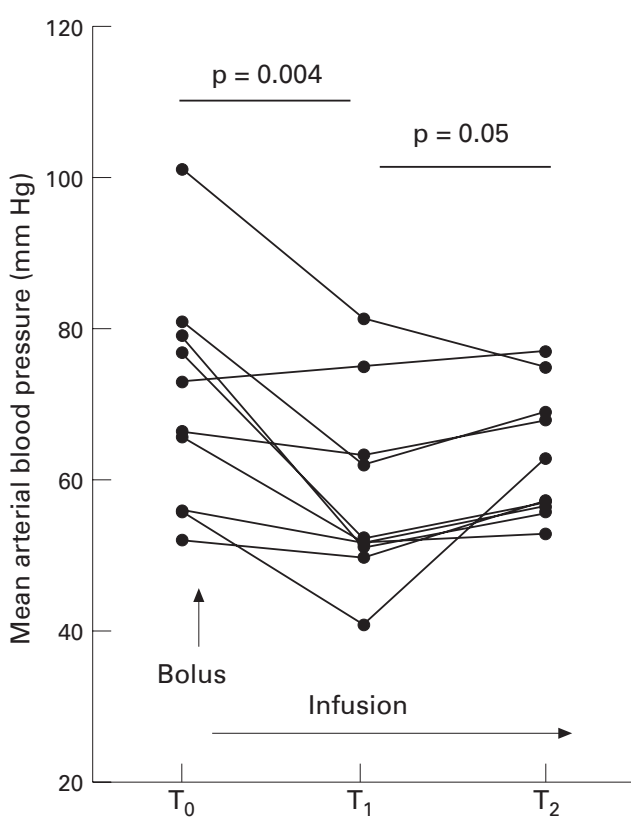

Figure 4 Effect of intravenous midazolam on mean arterial blood pressure.

0.005). The stroke volume, calculated in the same eight patients, fell by $20.3(3.1) \%$ between $\mathrm{T}_{0}$ and $\mathrm{T}_{1}(\mathrm{p}=0.003)$. Although stroke volume tended to increase from $T_{1}$ to $T_{2}$ (in six patients), this increase was not statistically significant $(\mathrm{p}=0.08)$, perhaps reflecting the changes in heart rate mentioned above.

There was no change in right atrial pressure or systemic vascular resistance with intravenous midazolam. The pulmonary vascular resistance increased slightly from $T_{0}$ to $T_{1}$ in the four patients with indwelling left atrial catheters, but this did not reach a level of statistical significance $(p=0.10)$.

\section{Discussion}

Effective sedation is an essential part of management of the ventilated patient. Although the ideal agent does not exist, midazolam has an onset of action of less than 15 minutes, a distribution half life of around 30 minutes and is water soluble, making it favourable for use in paediatric intensive care. ${ }^{211}$

In the early postoperative period after cardiac surgery - in response to rewarming, myocardial dysfunction, inotrope treatment, and cardiopulmonary bypass itself-a degree of haemodynamic variability is inevitable. Any additional cardiosuppressant effect of sedative drugs is likely to be amplified under such circumstances, and is therefore particularly undesirable.

Our study group was deliberately selected as a group of children with a normal cardiac output after cardiac surgery. Even so, there was a consistent fall in cardiac output after an intravenous bolus of midazolam. In no patient did the cardiac output fall to a critical level, and there were no major sequelae as a direct consequence of the bolus administration. None the less, these patients represent the 'better' end of the haemodynamic spectrum and it is not unreasonable to speculate that the effects of the drug could be even more important in children with a lower baseline cardiac output.

A fall in oxygen consumption has widely been reported in patients receiving intravenous midazolam. ${ }^{12}$ In our study group, oxygen consumption was continuously monitored by respiratory mass spectrometry for the one hour period, and in the seven children in whom we saw first a fall and then a rise in oxygen consumption, the 'trough' value was seen at between 12 and 20 minutes, with a subsequent increase to within $10 \%$ of baseline at one hour. In the remaining three children, the oxygen consumption did not recover over the study period. One of these patients (patient 5, in whom the cardiac output also continued to fall) developed a persistent low cardiac output state, and went on to require an increasing dose of inotropic treatment, intravenous colloid infusions and peritoneal dialysis. In the other two children, despite a small but continuing reduction in oxygen consumption during the intravenous midazolam infusion, the cardiac output fell by only a further $4 \%$ between 15 and one hour after the bolus in patient 7 , and increased to above baseline in patient 3 .

We do not suggest that an intravenous bolus of midazolam should be avoided under all circumstances, but perhaps it should be reserved for rapid sedation in the wakeful or agitated child, ${ }^{13}{ }^{14}$ so long as this is not in turn due to a low cardiac output. In the vast majority of children, in particular those who are already receiving other sedating agents, bolus administration of midazolam can, and should be, avoided.

CRITIQUE

'Wakefulness' is difficult to assess in the child who is already receiving intravenous morphine and neuromuscular blocking agents, and our markers of this were clinical. There was no spontaneous respiratory effort or movement, and no response to suction of the endotracheal tube in terms of tachycardia, hypertension, or a gag or cough reflex in any of the patients. Furthermore, one might expect the heart rate of the wakeful child to fall with intravenous sedation, but in response to a fall in cardiac output, this could naturally be counterbalanced by a reflex tachycardia in an attempt to augment cardiac output.

Had this study shown the changes in cardiac output only reflected oxygen consumption, it could be argued that a reduction in the oxygen demand of the peripheral tissues in the absence of any change in myocardial performance may have been desirable. However, the fall in mixed venous oxygen content after an intravenous bolus must reflect an increase in peripheral tissue oxygen extraction in response to reduced oxygen delivery (or cardiac output), and although we do not have any other measures of myocardial contractility, it is reasonable to infer that an intravenous bolus of midazolam negatively influences myocardial performance. The exact nature of the cardiovascular suppression seen in this and other studies ${ }^{11}$ remains uncertain. 
Benzodiazepines are frequently used together with opiates in intensive care, and there have been a number of studies investigating the combined sedative effects of the two groups of drugs. There is little doubt that opioids enhance the sedative effect of benzodiazepines, ${ }^{15}$ but there is uncertainty as to whether this represents summation or synergism. ${ }^{16}$ It is possible, therefore, that its combination with morphine in our study may have exaggerated the haemodynamic effects of intravenous midazolam, but this reflects the usual clinical scenario in these patients where a combination of pain relief and sedation is required.

\section{Conclusion}

In children who have undergone cardiac surgery an intravenous bolus of midazolam causes a transient but unwanted fall in cardiac output, with recovery during continuous infusion. We suggest therefore that in patients who are already receiving other intravenous agents which provide sedation, the use of intravenous midazolam should be limited to a continuous infusion.

We would like to thank Dr Michael Rigby, Dr Elliot Shinebourne, Mr Christopher Lincoln, and Mr Darryl Shore for allowing us to study their patients.

This work was supported by a LIFFE benefits grant, and by
allowing us to study their patients.

This work was supported by a LIFFE benefits grant, and by
the British Heart Foundation (Junior Research Fellowship FS/95029)

1 Squires RF, Brastrup C. Benzodiazepine receptors in rat brain. Nature 1977;266:732-4.

2 Amrein R, Hetzel W. Pharmacology of drugs frequently Amrein R, Hetzel W. Pharmacology of drugs frequently
used in ICUs: midazolam and flumazenil. Intensive Care used in ICUs: midazolan

3 Forster A, Gardaz JP, Suter PM, Gemperle M. I-V midazolam as an induction agent for anesthesia: a study in volunteers. Br f Anaesth 1980;52:907-11.

4 Lebowitz PW, Cote ME, Daniels AL, et al. Comparative cardiovascular effects of midazolam and thiopental in healthy patients. Anesth Analg 1982;61:771-5

5 Al-Khudhairi D, Whitwam JG, Chakrabarti MK, Askitopoulou H, Grundy EM, Powrie S. Haemodynamic effects of midazolam and thiopentone during induction of anaesthesia for coronary artery surgery. Br f Anaesth 1982; 54:831-5.
6 Marty J, Nitenberh A, Blanchet F, Zouioueche S, Desmonts JM. Effects of midazolam on the coronary circulation in patients with coronary artery disease. Anesthesiology 1986; 64:206-10.

7 Silvasi DL, Rosen DA, Rosen KR. Continuous intravenous midazolam infusion for sedation in the pediatric intensive care unit. Anesth Analg 1988;67:286-8.

8 Lloyd-Thomas AR, Booker PD. Infusion of midazolam in paediatric patients after cardiac surgery. Br $\mathcal{F}$ Anaesth 1986; 58:1109-15.

9 Davies NJH, Denison DM. The measurement of metabolic gas exchange and minute volume by mass spectrometry alone. Respir Physiol 1979;36:261-7.

10 Shekerdemian LS, Shore DF, Lincoln C, Bush A, Redington AN. Negative pressure ventilation increases the cardiac output in children after right heart surgery. Circulation 1996;94(suppl II):49-55.

11 Reves JG, Fragen RJ, Vinik HR, Greenblatt DJ. Midazolam: pharmacology and uses. Anesthesiology 1985;62:310-24.

12 Rosen DA, Rosen KR. Midazolam for sedation in the paediRosen DA, Rosen KR. Midazolam for sedation in the paedi-
atric intensive care unit. Intensive Care Medicine 1991;17: atric in $15-9$.

13 Shapiro JM, Westphal LM, White PF, Sladen RN, Rosenthal MH. Midazolam infusion for sedation in the intensive care unit: effect on adrenal function. Anesthesiology 1986;64:394-8.

14 Harding J, Kemper M, Weissman C. Midazolam attenuates the metabolic and cardiopulmonary responses to an acute increase in oxygen demand. Chest 1994;106:194-200.

15 Dundee JW, Halliday NJ, McMurray TJ, Harper RW. Pretreatment with opioids. Anaesthesia 1986;41:159-61.

16 Tverskoy M, Fleyshman G, Ezry J, Bradley EL, Kissin I. Midazolam-morphine sedative interaction in patients. Anesth Analg 1989;68:282-5.

\section{Appendix}

\section{ABBREVIATIONS}

BSA $=$ body surface area

$\mathrm{CaO}_{2}=$ arterial oxygen content

$\mathrm{CI}=$ cardiac index

$\mathrm{CvO}_{2}=$ mixed venous oxygen content

$\mathrm{Hb}=$ haemoglobin $(\mathrm{g} / \mathrm{dl})$

LAP $=$ left atrial pressure

MAP $=$ mean arterial blood pressure

MPAP = mean pulmonary arterial pressure

$\mathrm{PaO}_{2}=$ arterial oxygen tension

$\mathrm{PvO}_{2}=$ mixed venous oxygen tension

PVRI = pulmonary vascular resistance index

$\mathrm{RAP}=$ right atrial pressure

$\mathrm{SaO}_{2}=$ arterial oxygen saturation

$\mathrm{SvO}_{2}=$ mixed venous oxygen saturation

SVRI = systemic vascular resistance index

$\dot{\mathrm{V}}_{\mathrm{O}_{2}}=$ oxygen consumption 